\title{
The Path of Innovative Ecological Construction in Development Zone
}

\author{
Wenqing $\mathrm{Wu}^{1}$, Haiying Wang ${ }^{2}$, \\ ${ }^{1}$ Regional Science and Technology Policy Research Center, Shanxi University, Taiyuan City, China \\ ${ }^{2}$ Ideological and Political Theory Teaching and Research Department, Shanxi Polytechnic College, Taiyuan City, China
}

Email address:

why751024@163.com (Haiying Wang)

${ }^{*}$ Corresponding author

\section{To cite this article:}

Wenqing Wu, Haiying Wang. The Path of Innovative Ecological Construction in Development Zone. Science Research. Vol. 8, No. 6, 2020, pp. 119-124. doi: 10.11648/j.sr.20200806.11

Received: October 26, 2020; Accepted: November 5, 2020; Published: November 11, 2020

\begin{abstract}
The innovation ability of a country or region depends on whether it has a good innovation ecology, which is the important support of the modern innovation governance system. The creation of an innovative ecosystem concerns the fundamental nature of scientific and technological innovation and the future development of the region. Building a first-class innovation ecology should be vigorously promoted as a national or regional basic, overall, strategic task. As the main engine of regional economic and social development, the development zone should take the lead in the construction of innovative ecology, and create a big regional innovative ecology with the microclimate of industrial innovation in the development zone. Combining innovation ecological theories and field investigation, this paper holds that the ecological environment of innovation in the development zone should focus on the five aspects of the innovation. It includes innovation planning marked by prospective, scientific, practical and systemic, innovation model with innovation platforms, pilot production bases and mass entrepreneurship and innovation centers at its core, innovation system with emphasis on innovation research and development, industrial development, science and technology finance, evaluation and incentive, all kinds of innovative talents with future talents, talents in urgent need, reserved talents and innovation culture with incentive innovation, error management and social capital as the main body.
\end{abstract}

Keywords: Development Zone, Innovation Ecology, Innovation System, Innovation Culture

\section{Introduction}

The innovation ecosystem was first formally proposed by the President's science and technology adviser in 2003. In 2004 America's Commission on Competitiveness called for a new relationship between government, business and workers to build an innovation ecosystem for the 21 st century. [1] Innovation ecology is a social system formed by the combination of a series of factors related to innovation at the level of enterprises, industries, regions and countries. It is characterized by complexity, diversity, openness, dynamism, self-organization and habitat, etc. [2] In recent years, academic circles put forward the research consortium (RJVs) theory. According to it, as a cluster gathering place, the internal innovation logic of development zone lies in whether the innovation chain (network) interwoven by the three main bodies of industrial value chain, knowledge chain and innovation chain is perfect and optimized. Its internal innovation logic lies in whether the innovation chain (network) interwoven by the three main bodies of industrial value chain, knowledge chain and innovation chain is perfect and optimized, and the quality of the innovation chain (network) determines the strength and sustainability of the innovation ability of the development zone. The innovation ecological elements of development zone include innovation subject construction (enterprise main body construction, industrial main body construction, industrial layout), innovation carrier construction (construction of innovation infrastructure carrier and innovation platform), innovation service construction (intermediary service quality, administrative service quality, financing channels) and innovation environment cultivation (talent environment, policy environment, financial environment, legal 
environment, cultural environment, infrastructure) [3]. According to the innovation ecosystem theory, some scholars combined with the entrepreneurial practice of the development zone, have built a theoretical model of the innovation ecosystem of the development zone which consists of three parts: innovation input variable, innovation transformation variable and innovation output variable. Innovation input variables are mainly composed of innovation resource network elements, including innovation resource input at home and abroad and local innovation resource input. Innovation transformation variables are mainly composed of network elements of innovation entities, including management institutions, incubators, enterprise clusters, basic environment and facilities. Innovation output variables are mainly composed of local and domestic influences of innovation. [4] The academic circle also have summed up the common characteristics of innovation ecology in development zones: firstly, innovation resources are highly concentrated and rely on the innovation chain to form an efficient agglomeration advantage in development zones, which generates good economic benefits. The impeccable innovation chain can meet all-round needs of all kinds of innovative enterprises and further gather more innovative entrepreneurs. Secondly, it has formed different ways of combining government, industry, education and research. The allocation of resources between the government and the market is organically combined so that scientific and technological achievements can be more effectively industrialized and economic and social benefits can be realized to the maximum extent. Thirdly, policy promotion and planning guidance should be paid attention. At different times, forward-looking and strategic services and supporting policies are introduced for key industries. [5]

According to the existing research results, there are more theoretical discussions on innovation ecology and development zone innovation ecology, but less discussions on the practical level. Based on the existing theoretical research results, this paper puts forward the path of ecological innovation construction in the development zone. In order to create first-class innovation ecology, it is necessary to adopt multichained polymerization and efficient coupling of industrial chain, innovation chain, element chain, institutional chain and supply chain to integrate talents, finance, land and data, promote the rapid transformation of scientific and technological achievements, and form an ecosystem in which "seeds" of science and technology and industry break through the ground, "seedlings" grow vigorously, "small trees" accelerate the formation of timber and "big trees" gather into forests. [6] Specifically speaking, the development zone innovation ecological construction should be promoted from the following five aspects.

\section{Making Innovative Plans}

Innovation planning is the logical premise of innovation ecological construction in development zone. Looking at the trend of innovation development in the world, all countries attach great importance to innovation planning. In 2014, Britain released Our Growth Plan: Science and Innovation, placing science and innovation at the heart of its long-term economic development plan. In 2016, China issued the National Science and Technology Innovation Plan of the 13th Five-Year Plan, which puts forward the strategic goal of stepping into the ranks of innovative countries. The development zone should take the innovation plan as the important content and the key task of the medium and long term development plan, and strive to realize the plan to lead the innovation and drive the development with the innovation.

The first innovation plan of the development zone is to face the frontier of science and technology in the world, the major strategic needs of the country, the main battlefield of regional economic and social development, to clarify the shortcomings, to find the right entry point and focus, and to clarify the strategic objectives and key tasks. Second, the innovation ecological construction is regarded as the important content of the planning, with the focus on deepening the innovation in the mechanism of ecological construction and exploring the development model of innovative ecological construction. Third, the innovative planning of the development zone should be forward-looking, scientific, operational and systematic. It should make overall arrangements for the strategic objectives, objects and means of innovation, take planning as the main basis for the construction and development of innovative ecology in development zones, and give full play to the guiding and normative role of planning. The fourth, it is necessary to be open and compatible, entrust specialized agencies to carry out special consultations, participate in depth by experts and scholars, enterprise departments, and local governments, extensively consult the opinions of various innovative subjects and the public, and strive to maintain consistency with the regional planning in their respective regions, so as to enhance the recognition of the planning. [7] The fifth, it is necessary to establish a planning project system. The planning task is divided into the main body, the responsibility, the goal clear project, the resources are allocated according to the project priority, strictly implements the project management. The sixth, the planning and controlling mechanism should be established and improved. The whole process management of the implementation, adjustment, evaluation and examination of the plan should be carried out to maintain the seriousness of the plan, to perfect the information system, strengthen the planning supervision. Problems encountered in the implementation of the programme should be addressed in coordination with specialized agencies.

\section{Building Innovation System}

At present, the development power of the development zone is changing from factor input to innovation drive. It is inevitable to promote industrial upgrading through high-tech intensive industrial chain. [8] The innovation system of the 
development zone should grasp the core problems that must be paid attention to in science and technology from the whole, organize and mobilize different innovation subjects and resources more efficiently to strategic objectives. It is necessary to integrate many innovation units and elements efficiently around major strategic needs, dynamically combine effective innovation breakthrough ability, and form a large and deep interdisciplinary and whole-chain cooperation, so as to enhance the effectiveness and activate the vitality of the system. [9]

To build the innovation system of the development zone, first of all, it should strengthen the innovation main position of enterprises and basic research, increase investment in scientific and technological research and development, and promote the full coverage of $\mathrm{R} \& \mathrm{D}$ activities above a certain scale. Large enterprises should realize the leap from being to being strong, while small and medium-sized enterprises should complete the breakthrough from nothing to being. The second thing for the development zone to perform is to further increase the incentive for R \& D investment and innovation achievements of enterprises, open up the innovation chain, industrial chain and value chain of industry, university and research, expand innovative investment channels, realize the breakthrough of integrating scientific discovery, technological leap and industrialization direction, realize the effective link between knowledge innovation and future commercial ecology, strengthen the ability of independent innovation and speed up the realization of independent innovation with symbolic significance. The third through self-cultivation, open cooperation, the establishment of key laboratories and other innovative platforms to speed up the construction of new R \& D institutions to master and lead advanced technology. The development zone should give full play to the role of various research and development institutions to accelerate the breakthrough of new and high technologies by relying on the platform to tackle key problems. The Fourth, it is necessary to set up a "fund for the trial maturation and industrialization of scientific research achievements in the development zone ", broaden the types of landing projects in the development zone, and raise the level of industrialization landing projects in the development zone. Especially attract those projects that play a leading role in some new industries in the development zone. Furthermore, the development zone should build an open pilot base of scientific and technological achievements that integrates technology integration, maturation and engineering testing services, and promote the scale and industrialization of successful pilot maturation projects in a timely manner, so as to enhance the industrial chain level. The fifth, it is necessary to build a center for mass entrepreneurship and innovation to improve the planning and quality of mass entrepreneurship and innovation. It is suggested that first-class entrepreneurship and innovation operation team should be introduced to accelerate the attraction of high-end entrepreneurship and innovation resources such as leading enterprises and leading enterprises, promote the development of entrepreneurship and innovation with high quality, and guide and support a group of high-end scientific and technological talents, outstanding entrepreneurs, professional investors and highly skilled talents to become the main force of innovation and entrepreneurship.

\section{Improving the Innovation System}

The construction of the innovation ecology of the development zone can not be separated from the advanced and scientific innovation system. In the management activities, the development zone needs to form the systems, rules and regulations that are compatible with the innovative spirit and values of the park. and the development zone needs to form the system, rules and regulations suitable for the innovation spirit and innovative values of the park in the management activities. The innovation system of development zone mainly includes innovation management system, innovation incentive system, innovation evaluation system, innovation constraint system and so on.

The first measure of innovation system construction is strengthening scientific and technological innovation research and development. The focus of support will be shifted from product research and development in competitive fields to product research and development in basic research and key technologies through institutional guidance. The key of investment should be changed from technology catch-up strategy to technology advantage strategy. It focuses on replacing passive defense with aggressive efforts, shaping the leading edge of science and technology in the future, determining key areas, directions and projects based on the long-term development of science and technology, and strategically allocating scientific and technological resources. Secondly, improving the development mechanism of innovative industries. Through institutional guidance, the development zone should form an industrial driving force with new technologies, new industries, new forms of business and new model economy as its core, and strive to build an industrial cluster with independent intellectual property rights, leading enterprises, first-class R\&D platforms and teams, and complete industrial chains. The third, innovating the mechanism of attracting investment. Through the guidance of the system, the investment attraction of the development zone will be inclined to high-tech industry, strategic emerging industry and green high-end industry, with the emphasis on the introduction of projects with high scientific and technological content and strong innovation effect. The fourth, improving the system of science, technology and finance that supports innovation. The development zone shall actively promote science and technology and financial depth fusion, strengthen its financial resources to optimize configuration, flexibly use of its various financial instruments so as to supply the subjects of its innovation and industrial diversification, differentiation, customized financing services, and cover the whole process of science and technology innovation activity, the whole life cycle of enterprise development through a variety of system. In addition, the development zone should 
strive to improve the industrial science and technology venture investment system, and form a whole chain financial system consisting of seed fund, angel investment, guarantee fund, credit loan, government venture capital guidance fund, industrial fund and so on, so as to play a multi-directional, three-dimensional venture investment fund support for scientific and technological innovation. [10] In addition, the development zone also makes good use of various debt financing instruments, strengthens the multi-level capital market support, and creates conditions for enterprises to realize direct financing. The Fifth, to improve the evaluation and incentive system for development zones. Through the guidance of the system, the evaluation of scientific research projects, talents and institutions should be focused on the innovation, quality, contribution and influence of landmark achievements as well as the actual effect of innovative development in service development zones. The development zone should also rationalize the mechanism of allocation of scientific and technological resources, the salary and reward system, and the universal talent incentive mechanism, establish an overall and coordinated talent incentive policy, and an institutional environment conducive to scientific researchers' painstaking innovation. Sixth, to improve the international cooperation system. Through institutional guidance, the development zone should strengthen international cooperation in scientific and technological innovation, actively integrate into the global innovation network and chain, promote the open sharing and free flow of innovative resources, and realize the upgrading of scientific and technological strength. Seventh, to improve the system for supporting government services. Through institutional guidance, enterprises and scientists should be allowed to determine the direction and mode of use of innovative resources, so that they will be directed to supply-side structural reform, to economic and social development, and to a better life for the people. [11]

\section{Gathering Innovative Talents}

Innovative talents are the first resource for ecological innovation construction in the development zone. The development zone should not only firmly establish the strategic idea of leading the development with innovative talents, but also implement the strategy of attracting, gathering and retaining talents simultaneously. It should pay close attention to the development of human resources as it does to economic resources, attract talents as it does to investment, and pay close attention to the quality of talent projects as it does to project projects.

In order to gather innovative talents, first of all, the development zone should implement the open policy of talent introduction, commit major talent projects and find and recruit high-end talent in the global coordinate system." Hero posts" and "merit-based orders" will be widely distributed around the world, and a list of key technology solutions for enterprises will be released. Through "ranking the top of the list", the development zone can tackle scientific and technological problems, realize accurate docking between talents and enterprises. The second, to innovate mechanisms to use our talents. Relying on key platforms such as key laboratories, academician workstations, technology innovation centers, and scientific and technological achievements industrialization bases, THE DEVELOPMENT zone should intensify efforts to attract talents for flexible use and projects, so as to guide them to concentrate on leading industries and strategic emerging industries, high-end service industries, as well as enterprises based in the headquarters. Thirdly, to pay attention to the cultivation of future talents. By creating the soil for the growth of top talents, the development zone supports those top innovative talents. In addition to attracting talents, the development zone will become an ideal home for innovative talents to realize their dreams, and the innovation of the development zone will be introduced into the "no man's Land". Fourthly, to maintain talent vitality. Through the distribution of employment subsidies, unblocking the channels for the introduction of talents in colleges and universities, expanding the scale of internships in enterprises, establishing joint training bases between schools and enterprises, setting up "golden seed" scholarships in colleges and universities, and supporting innovation and entrepreneurship, we can attract young talents from universities and scientific research institutions, strengthen the reserve forces of new students, form a reasonable talent gradient, and give play to the main role of enterprises in attracting talents. The fifth, to create a comprehensive talent support system. Focusing on the ten elements of "reward, support, cultivation, service, housing, medical care, education, settlement, travel and honor", the development zone should give strong support to the innovation and entrepreneurship of talents at different levels and stages. We will carry out a special talent training program, build a high-quality medical education system with high standards, an all-round system for qualified personnel to live in peace, and a multi-level system for accurate services, so as to provide full chain and specialized comprehensive services for talents and build a high-quality talent community.

\section{Fostering Culture of Innovation}

Innovation culture is not only the forerunner of innovation behavior, but also the power source of science and technology innovation in the development zone. Culture will always influence whether, when, how and to what extent members of the development zone's willingness to innovate. What kind of culture there is, there will be what kind of innovation. It will inevitably produce corresponding innovation results. [12] The practice of Silicon Valley in the United States shows that the promotion of innovation, as an important success factor, is to form a culture that can give full play to people's creativity and create a habitat for entrepreneurship. [13]

Cultivating the innovation culture of the development zone, the first is to create an atmosphere of encouraging innovation. The development zone should actively carry out innovation 
publicity and education, strengthen the awareness of innovation in order to cultivate and form a value orientation that advocates innovation, innovates from the past, adheres to the new and dares to take the lead in the world, strengthen innovation confidence and cast the soul of innovation culture. The development zone should strive to create an environment that is universally recognized and respected by the innovation subject to consolidate the mass foundation and environmental foundation of innovative development. The third, to foster entrepreneurship and maker culture. By forming a guide to attract more talents to engage in innovative activities and entrepreneurial behaviors, planning innovation, promoting innovation and implementing innovation have all become voluntary action. [14] The fourth, to implement error management. The development zone should perfect a mechanism of tolerating failure and tolerating fault reasonably. By respecting the instantaneous, random and uncertain characteristics of scientific research inspiration, and especially by encouraging the new generation of employees to communicate, think and learn more, the innovation spirit and the sense of self-efficacy of all staff in the development zone can be inspired and cultivated. [15] The fifth, to cultivate social capital. By carrying forward the mission spirit of "WE THE FUTURE" and the spirit of "inclusiveness", the development zone can continuously strengthen the concept of grand collaboration, open up informal communication channels and build a "knowledge field". In addition, it also promotes the integration of talents with different knowledge and cultural backgrounds, provides equal opportunities for innovative entrepreneurs with different knowledge levels and cultural backgrounds, maximizes the value of innovation, and creates an organizational culture conducive to collective learning and collaborative cooperation among enterprises in the development zone.

\section{Conclusion}

Building an innovation ecosystem is a strategic move based on the present and the future. The most important thing for the development zone's innovation ecology construction is to incorporate it into the overall strategy of innovation planning and do a good job in the top-level design. In the process of construction, on the one hand, the development area should focus on the construction of innovation system, and build a scientific and complete innovation system as the core system to ensure the efficient operation of the innovation system. On the other hand, the development zone should take extraordinary measures to gather high-end talents needed by key industries, cultivate excellent innovation culture, and breed and promote major innovation achievements. In the long run, the development zones should resolutely remove the institutional obstacles which hinder innovation, unleash and stimulate the innovation vitality of all types of innovation entities to the greatest extent, and form an innovation ecosystem in which all types of innovation entities have the innovation ability, the innovation will and the innovation responsibility [16] so as to eventually lead the high-quality development of regional economy.

\section{Acknowledgements}

We are grateful to get the help of Fund projects:

1. Key soft science research project of Science and Technology Department of Shanxi province (Project No. 201804203-3). Title: Research on innovation development mechanism and policy of development zone in Shanxi province.

2. Shanxi Scholarship Council of China (Project No. 2020-155) Title: Research on the development path of Shanxi vocational education internationalization driven by the construction of "Double High Plan".

\section{References}

[1] Zhang H., Ma Z., 2020. Research on upgrading path of innovation ecosystem in National Independent Innovation Demonstration Zone [J]. Macroeconomic Research, 6: 89-101.

[2] Ren F., 2020. Some thoughts on 2035 innovation culture and innovation ecology construction in China [J]. China Science and Technology Forum, 5: 1-3.

[3] Cai S., Ou G., Zhao L., \& Bian Y., 2018. Research on ecological quality evaluation of innovation system in high-tech development zones -- A case study of high-tech zones in Hubei province [J]. Scientific Research Management, 87-94.

[4] Zhao H., 2007. Research on construction, evaluation and secondary entrepreneurship of innovation ecosystem in development zone [D]. Tianjin: Tianjin University.

[5] Xue Q., 2017. Build a sound innovation ecosystem [N]. The People's Daily, 7-24 (7).

[6] Yang W., 2020. Make every effort to foster a first-class innovation ecosystem and strengthen new growth drivers for economic transformation and development [J]. Forward, 4: 5.

[7] Du H., 2015. Spain's national program for scientific research and innovation and its implications for China [J]. Global Scientific and Economic Outlook, 4, 22-27.

[8] Research Group of Institute of Industrial Economics, Chinese Academy of Social Sciences., 2020. Key tasks and policy ideas of China's Regional Innovation System Construction during the 14th five-year Plan period [J], Economic management, 8: 5-16.

[9] Yu J., Guan K., Li Z., \& Chen F., 2020. Focus on key and core technologies and strengthen China's systematic capacity for scientific and technological innovation [J]. Proceedings of the Chinese Academy of Sciences, 8: 1018-1023.

[10] Zhang X., 2020. Research on optimization of industrial science and technology innovation system in pilot zone based on coordination [J]. Special Zone Economy, 2, 11-14.

[11] Ren Z., 2020. Emphasis on foundation and regional cooperation to build a first-class innovative ecological system [N]. Science and Technology Daily, 6, 23 (5).

[12] Wu J., 2012. Innovative culture: International comparison and enlightenment significance [J]. Journal of Tsinghua University (Philosophy and Social Sciences edition), 5, 151-158. 
[13] Feng Z., Fang X., \& Li Z., 2016. Shaping contemporary innovative culture and practicing five development concepts $[\mathrm{J}]$. Scientific Research, 1, 1-3.

[14] National Science and Technology Innovation Plan of the 13th Five-Year

Plan, http://www.gov.cn/zhengce/content/2016-08/08/content 5098 072.htm (2020-10-19).
[15] Jia J., Kong X., \& Wang S., 2020. Research on the influence of the atmosphere of error management on the innovative behavior of the new generation of employees [J]. Scientific Research Management, 9, 238-246.

[16] Zhao L., 2017. Improve the innovation environment and stimulate innovation vitality $[\mathrm{N}]$. China Science Daily, 11-27 (7). 